\title{
Análise da importância do ensino-aprendizagem de informática nas escolas
}

\author{
Analysis of the importance of teaching-learning of computer technology in schools \\ Análisis de la importancia de la enseñanza-aprendizaje de la tecnología informática en las escuelas
}

Recebido: 13/01/2022 | Revisado: 22/01/2022 | Aceito: 28/01/2022 | Publicado: 29/01/2022

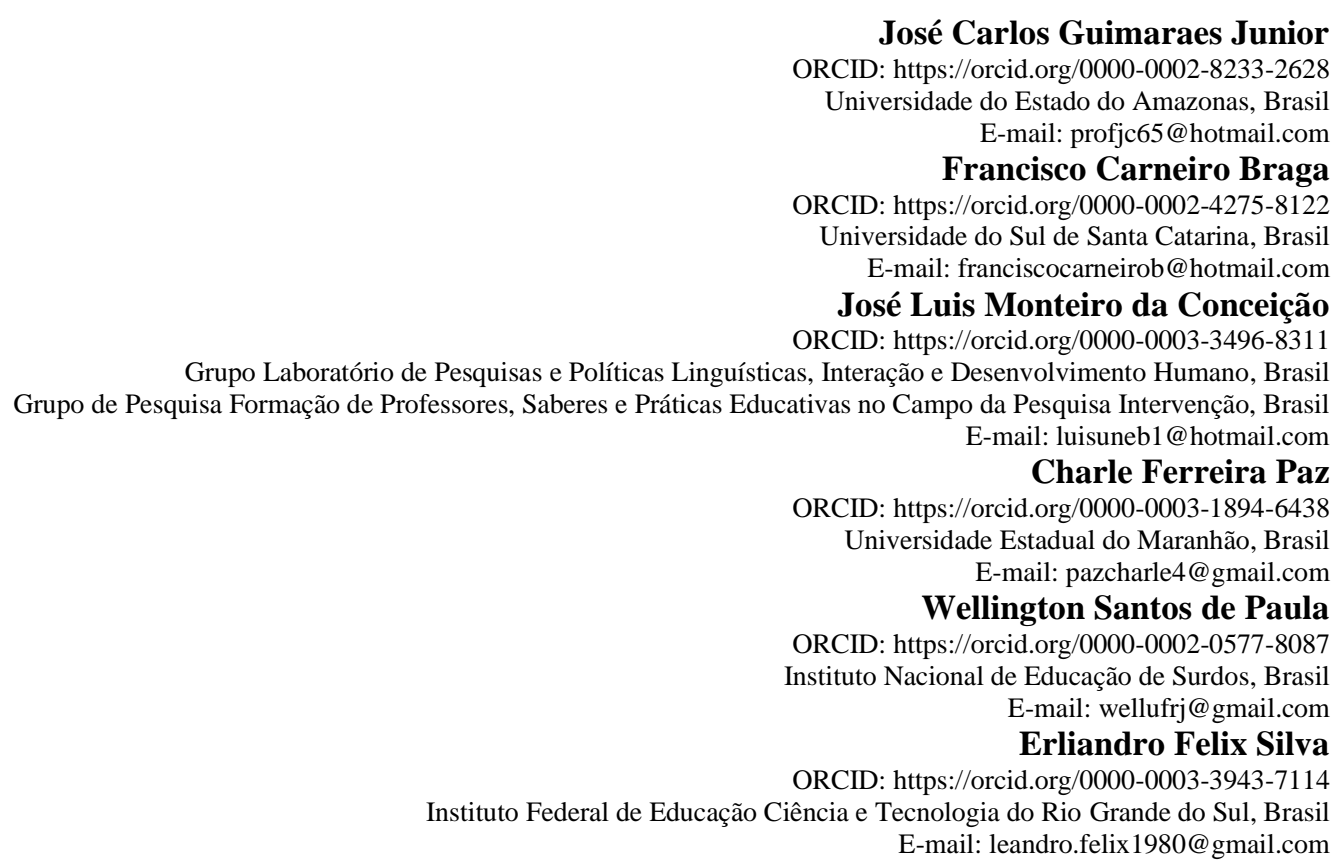

\section{Resumo}

Esse artigo tem como objetivo propor uma análise e discussão a respeito do uso da informática e seus benefícios nas escolas. Passamos por um momento delicado, delineado pela chegada dos computadores às escolas, pela imposição social e educacional em utilizá-los, além de serem considerados uma ferramenta imprescindível para o para o aprendizado e a manutenção de seus empregos em um mercado de trabalho cada vez mais competitivo. Uma parcela significativa de professores encontra-se despreparados e, todavia, cientes da iminente necessidade de empregar a informática como um elemento motivador e transformador de sua ação em sala de aula. Diante dessa realidade, a informática nas escolas, percebe-se o quanto os professores estão desamparados, onde continuam buscando uma solução mágica para resolver uma situação escolar problemática, no que se refere ao próprio desinteresse por parte do aluno, não somente do ponto de vista do uso dos computadores, mas também, pelo fato de não perceberem a necessidade e a importância de um aprendizado eficiente e eficaz, de maneira que possam estar preparados para enfrentar o mercado de trabalho em um momento posterior. Somado a essa realidade evidenciamos também a falta de preparo do professor para enfrentar esse novo desafio, onde a sua formação é postulada em um processo segmentado e sem nenhuma sequência lógica de aprendizado. Portanto, é a partir desse ponto que esse artigo busca evidenciar uma formação mais contínua desse professor, e aí destacamos a importância do aprendizado do uso da ferramenta informática, no seu dia a dia de sala de aula.

Palavras-chave: Informática; Educação; Escolas; Formação; Tecnologia.

\begin{abstract}
This article aims to propose an analysis and discussion about the use of information technology and its benefits in schools. We are going through a delicate moment, outlined by the arrival of computers to schools, by the social and educational imposition of using them, in addition to being considered an essential tool for learning and maintaining their jobs in an increasingly competitive. A significant portion of teachers is unprepared and, however, aware of the imminent need to use information technology as a motivating and transforming element of their action in the classroom. Faced with this reality, computer science in schools, it is clear how helpless teachers are, where they continue to seek a magical solution to solve a problematic school situation, with regard to the student's own lack of interest, not only from the point of view the use of computers, but also because they do not realize the need and importance of efficient and effective learning, so that they can be prepared to face the
\end{abstract}


job market at a later time. Added to this reality, we also evidence the lack of preparation of the teacher to face this new challenge, where their training is postulated in a segmented process and without any logical sequence of learning. Therefore, it is from this point that this article seeks to highlight a more continuous training of this teacher, and there we highlight the importance of learning to use the computer tool, in their day to day in the classroom.

Keywords: Informatics; Education; Schools; Training; Technology.

\section{Resumen}

Este artículo tiene como objetivo proponer un análisis y discusión sobre el uso de la tecnología de la información y sus beneficios en las escuelas. Atravesamos un momento delicado, marcado por la llegada de las computadoras a las escuelas, por la imposición social y educativa de utilizarlas, además de ser consideradas una herramienta imprescindible para aprender y mantener sus puestos de trabajo en un mundo cada vez más competitivo. Una parte importante de los docentes no está preparada y, sin embargo, es consciente de la necesidad inminente de utilizar las tecnologías de la información como elemento motivador y transformador de su actuación en el aula. Ante esta realidad, la informática en las escuelas, es evidente la impotencia de los docentes, donde siguen buscando una solución mágica para solucionar una situación escolar problemática, con respecto al propio desinterés del alumno, no solo desde el punto de vista el uso de las computadoras, sino también porque no se dan cuenta de la necesidad e importancia de un aprendizaje eficiente y efectivo, para que puedan estar preparados para enfrentar el mercado laboral en un momento posterior. Sumado a esta realidad, también evidenciamos la falta de preparación del docente para enfrentar este nuevo desafío, donde su formación se postula en un proceso segmentado y sin ninguna secuencia lógica de aprendizaje. Por tanto, es a partir de este punto que este artículo busca resaltar una formación más continua de este docente, y allí destacamos la importancia de aprender a utilizar la herramienta informática, en su día a día en el aula.

Palabras clave: Informática; Educación; Escuelas; Formación; Tecnología.

\section{Introdução}

Atualmente a tecnologia está presente em todos os lugares comuns, em todas as escolas, em todos os níveis de formação. Entretanto, não se pode negar que a informática tem se intensificado e se tornado imprescindível no nosso dia a dia em nossas vidas. Aos poucos, a informática torna-se uma forma corriqueira de comunicação em nosso meio social. Isto remete aos estudos de Moura (2012), o qual diz que a tecnologia nos tempos hodiernos é parte inseparável das relações sociais, sendo o meio responsável por conectar pessoas ainda que distantes umas das outras.

A realidade educativa no Brasil, desde a década de 70, propôs-se a elucidar os caminhos da informática educativa como ferramenta necessária ao processo de ensino e aprendizagem. Em 1979 é criada a Secretaria Especial de Informática (SEI), que tinha, entre outras incumbências, pesquisar os aspectos teóricos e a aplicabilidade dos computadores no processo de ensino e aprendizagem em todos os níveis de ensino (Santos Junior, 2021).

Há alguns anos postávamos cartas nos correios que demoravam em média três dias para chegar aos seus destinos; hoje em dia, passamos qualquer tipo de informação em tempo real, para qualquer lugar do planeta e, ainda por cima, contamos com uma diversidade de ferramentas que são capazes de traduzir todo nosso texto, com algumas alterações, para outra linguagem que necessitarmos. Progressivamente, todas as áreas vão fazendo uso deste instrumento e fatalmente todos terão de aprender a conviver com essas máquinas na vida pessoal assim como também na vida profissional e na sua base de formação, o indivíduo em fase escolar hoje conta com essa ferramenta para o desenvolvimento do seu aprendizado.

Atualmente, vivencia-se o que no entender de Kriezyu (2019) denomina-se como sociedade do conhecimento, período histórico em que as tarefas cotidianas humanas acontecem com a agregação das tecnologias, sendo a internet a mais representativa de todas. Voltando ao exemplo dos correios: nos dias de hoje é possível trocar mensagens pelos aplicativos comunicacionais, como, por exemplo, o Whats App (Silva et al., 2020). A informática está agregada a vida do ser humano e diante deste fato o presente estudo tem por objetivo destacar a importância do ensino-aprendizagem de informática nas escolas. É conveniente esclarecer que a interface e entre informática e educação não é algo novo, posto que a educação a distância 
(Bhowmick, 2019) já se notabilizava pela utilização dos recursos digitais para viabilização da aprendizagem, como, por exemplo, os ambientes virtuais de aprendizagem (Biancamano \& Flores, 2019).

$\mathrm{O}$ estudo consiste numa contribuição teórica e necessária para que o debate a respeito da magnitude do ato de aprender informática seja ampliado. Com o recente advento da pandemia do novo Coronavírus (Gama Neto, 2020; Lima, 2020), as instituições escolares se viram diante do desafio da migração abruta do modo presencial de ensino para o sistema remoto. No entender de Rondini, Pedro e Duarte (2020), esta é uma situação que de forma inevitável reflete em mudanças nas práticas pedagógicas professorais. Por conseguinte, este contexto evidenciou a problemática da exclusão digital no Brasil, com escolas se mostrando carentes de uma infraestrutura adequada para atuação no regime remoto emergencial (Carneiro et al., 2020).

\section{Metodologia}

A revisão bibliográfica tem como dois propósitos (Alves-Mazzotti, 1994), a construção de uma contextualização para o problema e a análise das possibilidades presentes na literatura consultada para a concepção do referencial teórico da pesquisa.

Sendo assim, nesse artigo, o material coletado pelo levantamento bibliográfico foi organizado por procedência, em artigos, teses, dissertações, em revistas, sites e vídeos (Gil, 2019; Zanella, 2013), onde a partir de análises críticas, permitiram aos autores a confecção desse material, que favoreçam a contextualização e a problematização teórica estudada nessa investigação. No que se refere a sua caracterização, a pesquisa se enquadra na categoria descritiva. Conforme Gil (2019) e Fontelles, Simões, Farias e Fontelles (2009), os estudos de cunho descritivo são aqueles em que o pesquisador procede com o detalhamento do fenômeno ou problema, analisando suas características, mas sem que se façam julgamentos sobre o mérito do conteúdo.

$\mathrm{O}$ aprofundamento das análises pode se constituir em estudo do tipo estado da arte. Nesta perspectiva, o patamar referente a produção científica de um determinado tema é analisado, com vistas a detectar tanto as temáticas mais recorrentes como também possíveis núcleos pouco explorados que carecem da geração de mais conhecimento (Romanowski \& Ens, 2006). No caso específico do presente artigo, foram consultadas tanto fontes mais clássicas que versam sobre informática nas escolas, bem como referências mais atuais que abordam sobre as barreiras que impedem a realização de práticas docentes mais assertivas quanto a informática e o uso de tecnologias educacionais nas escolas.

Por ser um estudo de caráter teórico, a prática de pesquisa não exigiu a realização de entrevistas, questionários ou ainda análise de estudos de caso (Yin, 2015). Estes são métodos que são aplicáveis num possível aprofundamento das temáticas aqui abordadas. Por meio de buscas na base de dados Google Acadêmico, foi possível localizar tanto as fontes mais recentes e materiais bibliográficos de outras épocas cuja pertinência foi avaliada para cumprir com o propósito do estudo. Assim, foi possível proceder com a construção do texto, primeiramente abordando a temática de forma mais geral para num segundo momento focalizar a questão da informática nas escolas considerando não só o contexto pandêmico da Covid-19 (Gama Neto, 2020; Lima, 2020) como também os problemas de infraestrutura presentes nas escolas (Carneiro et al., 2020).

\section{A Informática nas Escolas: Breve Contextualização}

Com o advento da Terceira Revolução Industrial, ocorrida a partir da segunda metade do século XX, o mundo passa a conviver com diversas descobertas que geraram grandes impactos não apenas no modo de fabricação de artefatos, mas também nas relações sociais: o computador e a internet (Zirondi \& Okada, 2021). Nas empresas, no comércio, na indústria e demais segmentos, os processos e serviços são mediados por ferramentas comunicacionais visando a praticidade e rapidez no atendimento aos usuários. Nas escolas não poderia ser diferente, onde os sites oferecem uma diversidade de fontes de 
informações importantíssimas aos nossos alunos, permitindo manipular a informação trata-las e armazená-las, através de pequenos processamentos de comandos.

O tímido uso de um editor de textos oferece condições para que o autor registre seus pensamentos e suas diversas formas de pensar de forma distinta daquela do texto manuscrito ou mesmo datilografado, ação essa que provoca no indivíduo uma forma diferente de ler e interpretar o que escreve, forma esta que se associa, ora como causa, ora como consequência, a um pensar diferente. Pode-se considerar que os seres humanos são criadores de técnicas que são aprimoradas constantemente. Assim, podemos compreender a informática como não sendo uma ferramenta neutra que simplesmente a utilizamos para apresentar ou registra determinados conteúdos ou pensamentos.

Desta forma, o processo de implantação da informática educacional na escola pública dar-se-á através de projetos de adesão elaborados pelas escolas, instalação de laboratórios de informática e capacitação de recursos humanos, como agentes multiplicadores. A partir daí, cria-se uma cultura escolar de uso das novas tecnologias de comunicação e informação e, em especial, do computador.

Esse assunto sempre foi cercado de polêmicas, posto que no início desse processo na década de 90, quando as escolas começaram a introduzir a informática nos seus processos de ensino- aprendizagem, percebeu-se, pela pouca experiência com essa tecnologia, um processo um tanto quanto caótico, fato esse que hoje em dia já tornou-se uma ferramenta normal no dia a dia dos professores e dos alunos; sejam quando em sala de aula ou mesmo no seu cotidiano. Conforme visto no estudo da autoria de Valente e Almeida (1997), a agregação dos computadores aos processos de ensino e aprendizagem nos anos 1990 não gerou mudanças no modo como os professores disseminavam os conteúdos, posto que, ainda de forma incipiente, os avanços pedagógicos ocorreram não por recomendação das escolas, mas sim provocadas pela própria evolução tecnologia ocorrida neste período.

O processo de introdução da informática nas escolas deu-se por uma demanda iminente de acesso a tecnologias, e por diante, ser um instrumento integrante dos diversos currículos escolares. Porém, nesses primeiros momentos em que essa tecnologia estava sendo aplicada nas salas de aulas, esses conteúdos eram ministrados de forma descontextualizadas, não oferecendo nenhum tipo de vínculo com as disciplinas oferecidas. Esta falta de contextualização remete ao que Saviani (2009) diz ser uma característica muito emblemática do ensino tradicional. Em contraponto a isto, D’ambrosio (2009) relata que o ensino para ser de qualidade e gerar os efeitos esperados de aprendizado no aluno deve se caracterizar pela contextualização, o que noutras palavras significa dizer que as temáticas abordadas em sala de aula são concatenadas com o cotidiano dos alunos.

Assim, e com o passar dos tempos, algumas escolas, percebendo o potencial dessa ferramenta introduziram o que foi tratado de informática educativa, onde além de oferecer o contato com os computadores, teve como objetivo o uso dessa ferramenta como instrumento de apoio às matérias e ao processo de ministrar as disciplinas.

Na década de 1990, surgem novos programas e exigem máquinas poderosas e eficazes, devido à incorporação de imagens e sons aos computadores e o desenvolvimento de softwares e hardwares. Estes computadores, além do processamento de dados, reúnem: fax modem, secretária eletrônica, scanner, acesso à Internet e drives de CDs e DVDs. A partir do ano 2000, os computadores estão presentes em quase todos os aspectos de nossa vida, quer seja no talão de cheques, seja no telefone, no crediário da loja, no cartão de crédito, em casa, na educação ou em qualquer outra situação.

No que se refere ao computador, pode-se depreender que ele consiste numa máquina feita para testa hipótese ou ideias e é deste processo que se torna possível a interação entre indivíduos, ainda que estes não estejam presentes lado a lado (Almeida, 2000). Sendo um equipamento que assume cada vez mais diversas funções, e dessa forma, contribui de forma significativa para uma elevação da produtividade, diminuição de custos e uma melhoria da qualidade dos produtos e serviços. Não podemos esquecer também, que o computador oferece também opções de divertimento para seus usuários, com opções infinitas. 
Por meio da Internet, é possível ignorar o espaço físico, conhecer e conversar com pessoas sem sair de casa em tempo real, digitar textos, formatar imagens, dentre outras opções. Não seria exagero afirmar que a internet nos tempos hodiernos representa um meio necessário para a organização das atividades em diversos campos de atuação (Castells, 2003). A internet é um instrumento fantástico devido a sua grande capacidade de armazenamento de dados e a facilidade na sua manipulação não podemos esquecer de que essa ferramenta não foi proposta e desenvolvida com um fim exclusivamente pedagógico ou para escolas, porém não podemos excluí-la do processo de ensino e aprendizagem; o grande desafio é, e será ainda por um bom tempo, como equacionar o uso da informática, através de suas ferramentas, com técnicas de ensino direcionadas para o nível de aprendizado que os usuários (alunos) estejam passando; ou seja, com fazer o bom uso.

É indispensável usá-la em favor de educação mais dinâmica, como auxiliadora de professores e alunos, de maneira a promover um aprendizado mais consistente e mais eficaz, dentro de uma realidade de mundo existente (Oliveira \& Silva, 2019). As tecnologias, assim, fazem parte das necessidades e competências que o professor precisa ter no decorrer do processo de ensino e aprendizagem. Partindo da compreensão do processo político-pedagógico como trabalho coletivo estar-se-á minimizando o individualismo e maximizando a socialização dos conhecimentos produzidos. Em igual tempo, estarão materializando o trabalho educativo pedagógico em atividades de aprendizagem. São estas atividades os elementos mediadores na aproximação dos conceitos científicos necessários ao saber.

$\mathrm{Na}$ educação a informática vem sendo usada tanto pra poder ensinar sobre computação, quanto pra ensinar qualquer coisa por intermédio do computador, dessa forma as escolas tem utilizado em sua estrutura de ensino essa ferramenta. O professor deve procurar constantemente depurar sua prática, o seu conhecimento. Sua atitude transforma-se em um modelo para o aluno, uma vez que ele está vivenciando a experiência do saber e compartilhando-a com o alunado, contribuindo assim para a geração de saberes no contexto escolar (Valente, 1993).

Jonassen (1996) classifica a aprendizagem em: aprender a partir da tecnologia (learning from), em que a tecnologia apresenta o conhecimento, e o papel do aluno é receber esse conhecimento, como se ele fosse apresentado pelo próprio professor; aprender acerca da tecnologia (learning about), em que a própria tecnologia é objeto de aprendizagem; aprender através da tecnologia (learning by), em que o aluno aprende ensinando o computador (programando o computador através de linguagens como Basic e Logo); aprender com a tecnologia (learning with), em que o aluno aprende usando as tecnologias como ferramentas que o apoiam no processo de reflexão e de construção do conhecimento.

Não obstante, o uso da tecnologia não se identifica como um propósito determinante, mas sim na forma de se utilizar essa ferramenta usando como estratégia cognitiva no processo de ensino aprendizagem, e assim ao invés de se oferecer essa ferramenta tecnológica no processo de ensino, os alunos ainda necessitam identificar a importância dessa ferramenta no seu dia a dia, seja na escola ou no seu cotidiano.

Portanto, a escola e seus professores, devem discutir e compreender a magnitude da informática nos processos de ensino-aprendizagem no mundo das relações sociais, uma vez que a informática exerce um papel muito forte na formação do aluno no seu comportamento individual e social, modificando, muitas vezes as concepções e o papel dos educadores.

Pode-se considerar que os avanços tecnológicos evidenciam a necessidade premente da preparação das crianças e dos jovens no sentido da preparação para a operacionalização das ferramentas informacionais e comunicacionais (Setzer, 1994). A distância existente entre as especificidades realizadas a partir do uso da informática e as metodologias do ensino tradicional de sala de aula, constitui-se ainda um enorme desafio para o professor, e para superar esse desafio faz-se necessário interpretar esta inserção de acordo com o contexto educacional vivenciado pelo aluno-professor nesse ou naquele instante, onde é preciso recriar, sem destruir o sentido real do seu aprendizado.

Segundo Cabral (2020), as tecnologias educacionais representam excelentes recursos para o aprimoramento e dinamismo dos processos de ensino e aprendizagem. Isto significa que ao utilizar corretamente estas tecnologias, o docente 
pode obter melhor performance no que se refere ao alcance dos objetivos de aprendizagem (Zabala, 1998). Todavia, consoante o que se lê em Sá e Nabais (2020), as tecnologias educacionais representam o complemento necessário para fazer com que o aluno compreenda assertivamente as temáticas debatidas em sala de aula, permanecendo sob a figura do professor a responsabilidade por mediar os processos de ensino e aprendizagem junto aos seus alunos.

Informática Educativa caracteriza-se pelo uso da informática como uma ferramenta do aprendizado em sua sala de aula, no qual o professor utiliza os recursos colocados à sua disposição (Oliveira, 1997). A Informática Educativa deve privilegiar a sua utilização como uma ferramenta pedagógica que auxilia no processo de construção do conhecimento, devendo, dessa forma, considerar o computador como um meio e não um fim.

Cada aluno é único e diferente, com saberes e competências acumulados com a escola e com a vida, nesse sentido, cabe ao professor ampliar os conhecimentos que já possui e mobilizá-lo a buscar seu desenvolvimento pessoal, não só ensinando o processo da informática, mas também, mostrando como pode ser utilizada no seu cotidiano de vida, dessa forma o aprendizado interdisciplinar torna-se um pré-requisito fundamental pra o bom aproveitamento dos conteúdos estudados.

Todo esse processo de mudança deve ocorrer a partir do momento em que o professore pode providenciar mais realizações do que já está acostumado a fazer, utilizando-se de ferramenta tecnológica, e assim, dá-se início um processo de reflexão no seu modo de ministrar suas aulas, sempre analisando as respostas dos alunos aos usos das tecnológicas oferecidas. Isto remete aos estudos de Nóvoa (2012), o qual diz que um dos traços atitudinais do professor com vistas ao sucesso de sua carreira docente é a adoção de uma postura reflexiva a respeito da forma como ele leciona os assuntos em aula.

Assim, os professores evidenciam um grande desafio pela frente, ao se deparam com o infinito mundo na internet. Caberá a sua expertise em identificar e analisar todas as suas competências que serão desafiadas nesse novo momento, identificando as maiores e melhores formas de percepções que seus alunos desenvolvem a partir do momento que têm acesso à tecnologia e aos seus conteúdos.

Hoje em dia o acesso à informática nas escolas deve ser integrante obrigatório do projeto político pedagógico onde estarão definidas todas as expectativas e objetivos que a escola busca na sua proposta educacional. O processo de inserção da informática nas escolas deve ocorrer dentro de um processo previamente definido, em parceria com a coordenação de informática/professores, que buscarão articulação e a gerência de todo esse processo, buscando um processo de mobilização importante e contínuo, sempre engajado ao projeto pedagógico do curso.

\section{Informática nas Escolas: Lacunas Estruturais e Pedagógicas Evidenciadas pela Pandemia de Covid-19 no Brasil}

Considera-se que a informática representa um recurso pedagógico cuja utilização assertiva pode não apenas melhorar o patamar de aprendizagem dos alunos como também elevar o seu nível de engajamento e de participação nos processos de ensino (Santos, 2021). Todavia, para que este intento almejado possa se materializar na prática, é preciso que algumas lacunas que foram evidenciadas com a atual crise sanitária gerada pela pandemia de Covid-19 (Gama Neto, 2020; Lima, 2020) sejam devidamente preenchidas.

Esta situação inabitual acabou desvelando o caráter deficitário de muitas escolas no Brasil no que se refere a sua infraestrutura e organização curricular. Consoante o estudo de Carneiro et al. (2020), um dos maiores problemas percebidos no decurso da pandemia diz respeito as instituições escolares que não dispõem de uma infraestrutura tecnológica razoável para a operacionalização do ensino remoto. Isto faz com que aconteça o fenômeno conhecido como exclusão digital (Sonego et al., 2021). Neste sentido, faz-se necessário o empreendimento de políticas públicas que possam suprir esta necessidade, a qual não 
beneficia somente o campo da educação, mas toda a sociedade, incluindo comércio, indústria e prestação de serviços nas cidades mais longínquas do Brasil.

Por sua vez, Alves e Mamede (2020), a forma como as escolas organizam seus currículos, ainda embasadas nos materiais didáticos somados a oralidade dos professores fez com que a migração repentina do ensino presencial para o ensino remoto não fosse um processo dos mais tranquilos. Dito de outra forma: as instituições escolares, sobretudo aquelas atuantes na educação básica já possuíam um padrão de trabalho consolidado, o qual teve de ser substituído por outro de maneira veloz, sem a devida preparação dos docentes. Rondini et al. (2020) relatam que as mudanças ocorridas pela pandemia de Covid-19 nas práticas professorais foram inevitáveis, mas conforme o que se viu em Valente e Oliveira (1997), estas mudanças ocorreram muito por conta do aspecto conjuntural que se desenhou. Não havendo esta mudança de cenário, o aprendizado baseado no binômio livro-explicação ainda estaria vigente em boa parte das escolas brasileiras. Em síntese: a pandemia de Covid-19 maximizou a relevância da informática nos processos de ensino e aprendizagem.

Esta prática educativa baseada em livros e exposição oral dos docentes é uma característica emblemática do ensino tradicional (Saviani, 2009). Nesta perspectiva, o professor é expositor dos conteúdos com o alunado tendo sua participação reduzida ao papel de mero ouvinte. Isto remete a uma cultura enraizada em determinadas escolas, as quais demonstram grande dificuldade em reconhecer o quão importante é a informática para a aprendizagem dos alunos. O estudo feito por Conceição e Ferreira (2002) elenca as principais dificuldades enfrentadas por estas instituições: a) docentes mais do que acostumados a lecionar disciplinas no modo tradicional; b) resistência na adoção das inovações tecnológicas; c) sucateamento dos equipamentos de informática; d) infraestrutura tecnológica deficitária, e; e) ausência de formação adequada para os professores no que tange ao manuseio correto, bem como a agregação das tecnologias educacionais nas atividades professorais.

É acertado dizer que embora a informática nas escolas seja um instrumento necessário para que o itinerário formativo dos estudantes seja congruente com os padrões e paradigmas da sociedade do conhecimento (Kriezyu, 2019). Todavia, na realidade brasileira existem óbices políticos, econômicos, pedagógicos e culturais que impedem um reconhecimento mais nítido das escolas com relação ao aprendizado de informática nas escolas. Há também as ocasiões em que o poder público até demonstra a realização de iniciativas voltadas a este fim, mais precisamente na forma de fornecimento de materiais de informática para as escolas. Acontece que apenas o suprimento desta necessidade não é suficiente. Isto porque a formação adequada para que os educadores possam implementar as tecnologias educacionais nas suas práticas pedagógicas, bem como a manutenção periódica dos equipamentos são situações que ainda carecem de reforço nas escolas brasileiras (Schossler et al., 2021).

Nos casos em que as instituições escolares dispõem de uma infraestrutura tecnológica satisfatória, a qual permita aos seus docentes o manuseio de tecnologias educacionais, não somente as aulas se tornam mais interativas como também a própria organização das atividades docentes também se aprimora. Dentre as ferramentas existentes que podem colaborar para o alcance destes intentos, destacam-se o Google Meet e o Google Classroom (Teixeira \& Nascimento, 2021). O reconhecimento da relevância da informática aos processos de ensino e aprendizagem é oportuno não somente do ponto de vista pedagógico e didático, mas também serve para o aprimoramento da prática professoral. Para Carvalho et al. (2021), a agregação da tecnologia ao trabalho docente propicia além do dinamismo nas aulas os seguintes benefícios: a) a melhoria do planejamento pedagógico; b) o aumento no leque de opções para tornar mais fácil por parte dos alunos o entendimento sobre as temáticas disseminadas; c) potencialização na internalização dos conteúdos ensinados, e; d) elevação no nível de participação dos estudantes.

A popularização tanto da internet como também dos smartphones demonstra a revolução tecnológica vivenciada pela sociedade contemporânea. Esta é uma realidade que se mostra desafiadora para as escolas, posto que se faz necessário aliar os 
processos de ensino e aprendizagem com as necessidades dos educandos que em sua maioria já estão habituados ao manuseio destas inovações tecnológicas (Pedra, 2021).

Neste sentido, muito mais do que a utilização periódica dos laboratórios de informática, é necessário que as escolas possam ressignificar o aprendizado de informática pelos seus alunos. Isto vai além do cumprimento das matrizes curriculares: significa reconhecer o caráter indissociável que a tecnologia hoje demonstra nas atividades humanas. É por esta razão que o presente estudo corrobora com a ideia da ampliação do debate sobre a relevância da informática para a melhoria da experiência de aprendizado dos discentes, envolvendo professores, coordenadores, pedagogos e todas as demais partes interessadas. Isto colabora tanto para o refinamento do trabalho docente como também promove a inclusão e a cidadania digital no âmbito escolar (Di Felice, 2021).

\section{Considerações Finais}

A fim de que cada professor tenha condições de criar ambientes de aprendizagem que possam garantir o envolvimento de todos os alunos é preciso reestruturar o processo de formação, o qual assume a característica de continuidade. Há necessidade de que o professor seja preparado para desenvolver competências, tais como: estar aberto a aprender a aprender, atuar a partir de temas emergentes no contexto e de interesse dos alunos, promover o desenvolvimento de projetos cooperativos, assumir atitude de investigador do conhecimento e da aprendizagem do aluno, propiciar a reflexão, a depuração e o pensar sobre o pensar, dominar recursos computacionais, identificar as potencialidades de aplicação desses recursos na prática pedagógica, desenvolver um processo de reflexão na prática e sobre a prática, reelaborando continuamente teorias que orientem sua atitude de mediação, logicamente que cada aluno em seu nível de aprendizado, pois não podemos exigir que um aluno do ensino fundamental possa refletir de maneira profunda a respeito de um determinado tema explorado em sala.

Esses novos caminhos revelam uma ruptura com as práticas tradicionais e avançam em direção a uma ação pedagógica interdisciplinar voltada para a aprendizagem do aluno - sujeito envolvido no processo não somente com o seu potencial cognitivo, mas com todos os fatores que fazem parte do ser unitário, ou seja, fatores afetivos, sociais e cognitivos. Assim, a formação não pode ser dissociada da atuação, nem se limitar à dimensão pedagógica ou a uma reunião de teorias e técnicas. Esse processo de formação-ação promove a articulação do referencial teórico construcionista com as ideias de educadores e pesquisadores que trazem contribuições referentes ao uso do ciclo descrição-execução-reflexão-depuração.

Assim, o professor deve estar preparado para situações de aprendizagem que lhe propicie atuar como mediador e promotor do aprendizado, promovendo a reflexão, a depuração e a construção do conhecimento, em um ambiente onde o aluno é o sujeito da aprendizagem significativa.

Há que se salientar também que criar uma maior consciência da profundidade e alcance das relações entre a ciência, a tecnologia e a sociedade se revelam como uma das metas mais importantes que a educação deve perseguir se quer construir uma sociedade mais humana.

A metodologia que estrutura a formação e a atuação do professor pode ser a de projetos, onde buscará promover a articulação entre formação e pesquisa, formação na teoria e formação na prática, formação pessoal e formação profissional.

O professor deve atuar como agente de mudança, valorizando os interesses e necessidades de seus alunos ao utilizar como ponto de partida de seu trabalho pedagógico os conhecimentos cotidianos emergentes no contexto, os quais são trabalhados com o uso de todos os meios tecnológicos disponíveis, destacando-se os recursos da informática, em busca de melhor compreendê-los e de desenvolver uma educação emancipatória. Como sugestão para trabalhos futuros, recomenda-se um levantamento em estudos datados a partir de 2020 até o presente a respeito das dificuldades enfrentadas por professores a respeito do uso das tecnologias educacionais no ensino remoto emergencial. 


\section{Referências}

Almeida, M. E. (2000). Informática e formação de professores. Ministério da Educação.

Alves, G. L. \& Mamede, S. (2020). Quando uma pandemia expõe as limitações da escola e da educação ambiental formal. Revbea, $15(4), 175$ - 189.

Alves-Mazzotti, A. J., (1994). Do trabalho à rua: uma análise das representações sociais produzidas por meninos trabalhadores e meninos de rua. Tecendo saberes, $60-78$.

Bhowmick, A.K. (2019). Distance education: a revolution in the Indian Education System. Distance Education, 1(9), 104 - 108.

Biancamano, M. R. \& Flores, A. P. P. (2019). O ambiente virtual como lócus da formação em Justiça Restaurativa: relato de uma experiência inovadora. Informática na educação: teoria \& prática, 22(3),

Cabral, F. H. M. (2020). Utilização do aplicativo Plickers no ensino de Matemática. Revista Brasileira de Educação Profissional e Tecnológica, 1, 1 - 12.

Carneiro, L. A., Rodrigues, W., França, G. \& Prata, D. N. (2020). Uso de tecnologias no ensino superior público brasileiro em tempos de pandemia COVID19. Research, Society and Development, 9(8), $1-18$.

Castells, M. (2003). A galáxia da Internet: reflexões sobre a Internet, os negócios e a sociedade. J. Zahar.

Cavalcante, T. C. D. C. V., David, P. B. \& Vasconcelos, F. H. L. (2021). Percepções sobre as políticas públicas de inclusão digital na educação básica durante a pandemia da Covid-19: uma análise bibliográfica. Conex. Ci. e Tecnol., 15, 1 - 11.

Conceição, J. L. M., \& Ferreira, F. N. (2022). Tecnologias da informação e comunicação na educação: desafios, possibilidades e contribuições para ensino e aprendizagem. Educar Mais, 6, 126 - 138 .

D’ambrosio, U. (2009). Educação matemática da teoria à prática. Papirus.

Di Felice, M. (2021). A cidadania digital: a crise da ideia ocidental de democracia e a participação nas redes digitais. Paulus Editora.

Fontelles, M. J., Simões, M. G., Farias, S. H \& Fontelles, R. G. S. (2009). Metodologia da pesquisa científica: diretrizes para a elaboração de um protocolo de pesquisa. Revista paraense de medicina, 23(3), $1-9$.

Gama Neto, R. B. (2020). Impactos da covid-19 sobre a economia mundial. Boletim de Conjuntura (BOCA), 2(5), 113 - 127.

Gil, A. C. (2019). Como elaborar projetos de pesquisa. Atlas.

Jonassen, D. (1996). Using Mindtools to Develop Critical Thinking and Foster Collaborationin Schools. DH Jonassen (1996). Computers in the Classroom: mind tolls for critical thinking. Columbus: $\mathrm{OH}$ : Merril/Prentice Hall, $23-40$.

Kriezyu, S. D. (2019). Language development through drama in preescholers. European Journal of Language and Literature Studies, 5(1), 15 - 22.

Lima, R. C. (2020). Distanciamento e isolamento sociais pela Covid-19 no Brasil: impactos na saúde mental. Physis: Revista de Saúde Coletiva, 30,1 - 10.

Moura, D. H. (2012). A organização curricular do ensino médio integrado a partir do eixo estruturante: trabalho, ciência, tecnologia e cultura. Revista Labor, $1(7), 1-19$.

Nóvoa, A. (2012). Devolver a formação de professores aos professores. Cadernos de Pesquisa em Educação, $18(35), 11$ - 22.

Oliveira, R. (1997). Informática educativa: dos planos e discursos à sala de aula. Papirus.

Oliveira, J. L. \& Silva, M. P. (2019). O uso das tecnologias no ensino fundamental em uma escola pública em Araguatins - TO. Revista Humanidades $e$ Inovação, 6(10), $155-168$.

Pedra, M. N. (2021). Tecnologia educacional como suporte no processo de ensino/aprendizagem. Revista de Administração do Cesmac, 9 , 95 - 104.

Romanowski, J. P. \& Ens, R. T. (2006). As pesquisas denominadas do tipo “estado da arte” em educação. Revista Diálogo Educacional, 6(19), 37 - 50.

Rondini, C. A., Pedro, K. M. \& Duarte, C. S. (2020). Pandemia do Covid-19 e o ensino remoto emergencial: mudanças na práxis docente. Interfaces Científicas - Educação, 10(1), $41-57$.

Sá, M. C. \& Nabais, A. S. Que importância atribuem os estudantes de Enfermagem às novas tecnologias. New Trends in Qualitative Research, 2 , 283 - 296.

Santos, D. M. A. A. P. (2021). As novas tecnologias e suas implicações na superação das dificuldades de aprendizagem: um enfoque à informática como recurso pedagógico. Revista Processando o Saber, 13, 44 - 59.

Santos Junior, R. L. (2021). Potencialidades da interação humano-computador na realidade tecnológica do Pará. R. Bibliomar, $20(2), 159$ - 182.

Saviani, D. (2009). Formação de professores: aspectos históricos e teóricos do problema no contexto brasileiro. Revista Brasileira de Educação, 14(40), 143 155 .

Schossler, A. B., Medeiros, L. M., Paprosqui, J., Germani, A. R. M. \& Folmer, I. (2021). Inclusão digital nas escolas do campo. Research, Society and Development, 10(5), $1-9$. 
Research, Society and Development, v. 11, n. 2, e42411225708, 2022

(CC BY 4.0) | ISSN 2525-3409 | DOI: http://dx.doi.org/10.33448/rsd-v11i2.25708

Setzer, W. W. (1994, setembro). Computadores na educação: por quê, quando e como. In: Anais do $5^{\circ}$ Simpósio Brasileiro de Informática na Educação (pp. $220-233)$

Silva, R. O., Martins, P. U. F. \& Nascimento-e-Silva, D. (2020). Analysis of WhatsApp as a communicational tool for a participative management in pedagogical spaces. Research, Society and Development, 9(12), 1-22.

Sonego, A. H. S., Silva, J. S. \& Behar, P. A. (2021). Estratégias pedagógicas no ensino remoto: possibilidades para diminuir a exclusão digital. Renote, 19(1), $62-72$.

Teixeira, D. A. O., \& Nascimento, F. L. (2021). Ensino remoto: o uso do Google Meet na pandemia da Covid-19. Boletim de Conjuntura (BOCA), 7(19), 44 92.

Valente, J. A. (1993). Computadores e conhecimento: repensando a educação. Unicamp.

Valente, J. A. (1997). Visão analítica da informática na educação no Brasil: a questão da formação do professor. Revista Brasileira de Informática na Educação, 1(1), $45-60$.

Yin, R. K. (2015). Estudo de caso: planejamento e métodos. Bookman.

Zabala, A. (1998). A prática educativa: como ensinar. Artmed.

Zanella, L. C. H. (2013). Metodologia de pesquisa. Departamento de Ciências da Administração/UFSC.

Zirondi, J. M. \& Okada, R. H. (2021). Manufatura avançada: a indústria 4.0 e seus desafios e oportunidades. Interface Tecnológica, $18(1), 593$ - 605. 